\title{
The impact of aspect ratio on aerodynamic performance and flow separation behavior of a model wing composed from different profiles
}

\author{
Abdulhalim Aşkan \\ Erciyes University, Kayseri, Turkey, aaskan@erciyes.edu.tr, ORCID: 0000-0002-0205-3961 \\ Selim Tangöz \\ Erciyes University, Kayseri, Turkey, stangoz@erciyes.edu.tr, ORCID:0000-0002-8284-1326 \\ Arrived: 17.08.2018 Accepted: 21.11.2018 Published: 31.12.2018
}

Abstract: In this study the impact of aspect ratio on the aerodynamic performances and flow separation behavior were investigated on a model wing made up four different profiles used to the wing of the Boeing 737-Classic aircrafts. The experiments were carried out in a wind tunnel with low speed at different angles of attack ranging from $-4^{\circ}$ to $40^{\circ}$ and at the $2 \times 10^{5}$ Reynolds number on wing models having different aspect ratios (0.7-1.3).

It was observed from the experiments and numerical studies that the changing of the aspect ratio affected the drag and lift and flow separation. The highest lift/drag ratio has been measured from the wing having aspect ratio of 1.3 at angle of attack of $7^{0}$. Moreover, the airflow was flowed as laminar in the areas near the middle of the wing until angle of attack of $24^{\circ}$. But, the flow was disturbed at wing tip due to vortex. The separation bubbles have been seen at $24^{\circ}-32^{\circ}$ for all aspect ratios. In addition, the increase of angle of attack caused the bubbles form clearly for 1.1 and 1.3 aspect ratios. Finally, the increases in aspect ratio and in angle of attack have been triggered flow separation.

Keywords: Different profiles, Low Reynolds number, Aspect ratio, Flow separation

Cite this paper as:

Asskan, A., Tangöz, S., The impact of aspect ratio on aerodynamic performance and flow separation behavior of a model wing composed from different profiles. Journal of Energy Systems, 2018; 2(4): 224-237, DOI: 10.30521/jes.454215

(C) 2018 Published by peer-reviewed open access scientific journal, JES at DergiPark (www.dergipark.gov.tr/jes)

\begin{tabular}{r|l} 
Nomenclature & \\
\hline AoA & Angle of attack \\
$A R$ & Aspect ratio \\
$C_{D}$ & Coefficient of drag \\
$C_{L}$ & Coefficient of lift \\
$\mathrm{CL}_{\max }$ & Maximum lift coefficient \\
$\mathrm{C}_{\mathrm{P}}$ & Coefficient of pressure \\
$\mathrm{Re}$ & Reynolds numbers \\
$x / c$ & Location along the chord $(\mathrm{mm} / \mathrm{mm})$ \\
$\mathrm{z} / \mathrm{b}$ & Location along the span $(\%)$ \\
Exp. & Experiment \\
\hline \hline
\end{tabular}




\section{INTRODUCTION}

A significant part of the accidents that occur on airplanes are triggered by different factors during landing or take off and stall which are expressed as the inability of the aircraft to hold in air. The reason for the occurrence of the stall event is that the airflow on the wing surface is undesirably separated and the carrying force holding the aircraft in the air drops below the limits of the balance weight of the airplane. The separation on the wing surface, which is the cause of the stall event, occurs at low speeds and high angle of attacks. One of the most important factors influencing airflow separation is the aerodynamic characteristics of the profiles forming the wing shape. The features of the profiles, such as the hunchback and the thickness, affect the lift force and the drag force of the wing, and therefore directly influence the stall character. Another important parameter that affects the air holding of the aircraft is the aspect ratio of the wing. The wing aspect ratio, which represents the ratio of the wing length to the average wing cord, affects the lift force and the drag force that creates resistance to the movement of the wing. That is why it is an important parameter that determines the performance of the wing and affects the stall character of the wing.

The goal of the performance of the wing aspect ratio is to reduce the stall speed by minimizing the flow separation on the wing, thus reducing the accidents to a minimum by ensuring that the aircraft is held in the air even at very low speeds. Many studies have been made in the literature for this purpose. The effect of aspect ratio on wings aerodynamic performance was experimentally investigated by Makoto Mizoguchi and Hajime Itoh [1] the range of $2.6 \times 10^{4}$ and $7.6 \times 10^{4}$ low Reynolds numbers on rectangular wings. The aerodynamic coefficients measured in the experiments were checked with the visualized flow areas and the theoretical results. After analyses, it was seen that at low Reynolds numbers, the performance of the wings which have high aspect ratio were affected by the separation bubbles formed at the leading edge of the wing. However, for wings having an aspect ratio of 3.0 and above, qualitative properties did not change much. It has been observed that the properties of the wings having an aspect ratio smaller than 3 are very different from those of the above-mentioned large aspect ratio wings. Significant changes have been obtained especially in the wings having an aspect ratio of 1 and less than 1. It was concluded that this AR effect was the result of wing edge vortexes.

In their another study, Makoto Mizoguchi and colleagues [2] have showed the effect of aspect ratio on wing performance and on the stall behaviors of the wings at the low Reynolds numbers $\left(\mathrm{Re}=5.2 \times 10^{4}\right)$ on the rectangular wings with experimental studies. The leading-edges and trailing-edges of the wings were plain, thus, the chord-wise transversal section of the wing model was rectangular. The cord length and thickness of the wing models having a rectangular planform and flat side edges were $90 \mathrm{~mm}$ and 1 $\mathrm{mm}$, respectively. The aspect ratio ranges from 0.5 to 1.5 at intervals of 0.1 and the experimental studies were carried out in the wind tunnel with low speed. Results have shown that the wings having a low aspect ratio are very sensitive to the change of the aspect ratio. It has been observed that as the aspect ratio decreases, the angle which maximum lift coefficient $\left(\mathrm{CL}_{\max }\right)$ taken is increases. It has also been observed that slight changes in the aspect ratio of 1.0 to 1.3 have caused significant changes in the aerodynamic characteristics of the wings. When the aspect ratio approaches 1.0 the angle of stall had also increased considerably.

Gabriel E. Torres and Thomas J. Mueller [3] investigated lift force, drag force and pitch moment behaviors of wing models of low aspect ratio working the range of $7 \times 10^{4}-2 \times 10^{5}$ low Reynolds numbers. As a part of this research the experts investigated the wings having the aspect ratios between 0.5 and 2.0, four different models, $2 \%$ thickness/chord ratio and 5/1 elliptical leading edges have been carried out at the wind tunnel. The results have outlined that great nonlinear curves in the lift force graphs, especially for $\mathrm{AR}<1.25$. The high values of maximum lift coefficient and corresponding angle of attack were also found for the models having low aspect ratio. Wing model was observed to have important aerodynamically influences. When AR value was below 1.0 and the angle of attack was high angle, the 
inverse Zimmerman models was found as the best model between the platforms. The elliptical planforms were found as the best model according to aerodynamically behaviors at low and middle angles for high aspect ratio.

Lance W. Traub [4] was conducted an analytical study to determine the impact of aspect ratio on the efficiency of ClarkY and an SD7062 wing models in low Reynolds numbers. The experiments were conducted in a wind tunnel having low-speed and open-return system. The turbulence intensity of the wind tunnel of $0.5 \%$ was measured as $1 \%$ and uniformity within the core of the tunnel. The analysis initially was implemented within the framework of a constrained planform area and weight. It was seen that from the results without the inclusion of airfoil pressure drag, wing efficiency increases essentially unbounded with aspect ratio. Also, the results showed that including the effects of pressure drag yielded the appearance of distinct peaks in $\mathrm{L} / \mathrm{D}$ and $\mathrm{C}_{\mathrm{L}}{ }^{3 / 2} / \mathrm{C}_{\mathrm{D}}$, which migrated to lower aspect ratio as the airfoil efficiency dropped.

In the another experimental study on the influence of aspect ratio, Liu and Hsiao [5] were analyzed the aerodynamic properties of the wing model having different aspect ratios in the range of $1.0 \leq \mathrm{AR} \leq 3.0$ in critical Reynolds numbers $\left(10^{4}\right.$ and $\left.10^{5}\right)$. The results indicated that when the aspect ratio was less than 1.6, the high stall angle and twist lift force were clearly indicated due to the nonlinear rising in the curves of lift force. The results also concluded that the flow streamline of wing model having low aspect ratio could be separated into three types of flow characteristics. When AoA value was less than $20^{\circ}$, the tip vortex was clear seen near the wing tip and was grouped up by the increasing of the angle of attack. The rising of AoA caused the flow reconnected and constructed the flow. When AoA value reached up to $30^{\circ}$, the reconnected of flow was maintained. But, the vortex shedding was disappeared and gradually altered by the large vertical flow.

Another study by Gavin K. Ananda and his colleagues [6] is concerned with examining the aerodynamically behaviors of the wings at low Reynolds numbers. Experimental investigations of ten flat and conical wings with aspect ratio ranging from 2 to 5 were carried out at Reynolds number ranging from 50,000 to 150,000 . The tests were experimented in the wind tunnel and the oil method was used for air flow scanning. The results of tunnel tests had displayed that the hysteresis was not monitored on all flat wing models. The values of lift coefficient were measured between 0.55 and 0.7 for all wing models. In addition, when the $\mathrm{C}_{\mathrm{Lmax}}$ results compare with the result obtained from low aspect ratio wing $(\mathrm{AR} \leq 2)$ tests in literature, the $\mathrm{C}_{\mathrm{Lmax}}$ values for the low to middle aspect ratio were seen to be minimally sensitive to change in aspect ratio value. It was also seen that in the flat and rectangular wings, the position of the aerodynamic center changed significantly with changing of the angle of attack. For the small angle of attack, while the center of aerodynamic near the quarter of the wing cord, at the high angle of attack (near the stall angle) the aerodynamic center was seen to tend to approach the trailing edge of the wing.

The near and wake flow on the rectangular wings having low aspect ratio $(\mathrm{AR}=1-2.5)$ at Reynolds number of $8 \times 10^{4}$ is investigated experimentally by Adam C. DeVoria and Kamran Mohseni [7]. The experiments carried out at the recirculating wind tunnel equipped with digital particle image velocimetry to visualize flow. The results obtained from time-averaged vorticity areas showed that as the aspect ratio increased, the flow separation reached the leading edge of the wing at lower incidence. It was seen that the rising of the aspect ratio values and the specification of the flow separation leaded to the velocity fluctuations. And then, the fluctuations associated with the rear edge shear layer also increased. Due to the reattached flow to the surface of the wing having $A R=1.0$, the large turbulent kinetic energy were bound to the separation bubbles of the leading edge. Moreover, the increasing of the angle of attack caused the vortices became narrower and more arranged with the model cord.

To determine the influence of aspect ratio on membrane wings and rigid flat test plates Zheng Zhang and colleagues [8] carried out a series of experiments at $\operatorname{Re}<51,000$ and various aspect ratios (0.9-4.3). The membrane wing models were made up from aluminum which its surface was coated by silicone rubber. The three aluminum frames had been $80 \%$ of the chord in width and $80 \%$ in depth. The fourth 
frame having $7.62 \mathrm{~cm}$ chord, $0.32 \mathrm{~cm}$ ribs and $0.21 \mathrm{~cm}$ thickness have been formed of $40 \mathrm{x} 80$ cell geometry. The tests have been carried out in a wind tunnel having low turbulence. The results obtained from tests showed that when the membrane wing compared with solid flat plate, the membrane wing had been a higher lift slope, stall-zone lift and aerodynamic performance. The values were approximately $15 \%, 10 \%$ and $12 \%$ higher, respectively. The properties induced by this membrane continue as the aspect ratio and Reynolds number decrease.

Ignacio Andreu Angulo and Phillip J. Ansell [9] have investigated the impact of the aspect ratio on the dynamic stall by comparing with the performances of the NACA 0012 wing at different aspect ratios $(\mathrm{AR}=3,4,5)$ with experimental measurements. The experiments were carried out on a wind tunnel having low speed, at two different Reynolds numbers $\left(\mathrm{Re}=4 \times 10^{5}, 5 \times 10^{5}\right)$ and frequencies $\mathrm{k}=0.1$ and 0.05 . The sinusoidal motion profile consisted of an angle of attack range between 4 and 22 degrees. It was found that the reduction of AR caused a reducing in the unsteady loading of the wing and delayed the dynamic stall duration similar to that viewed for the static stall of the finite wings.

Many of the previous study [1-11] on aspect ratio have usually been carried out by changing the dimensions of a certain profile or wing. In the current study, the influence of aspect ratio was investigated by changing the length of a wing consisting of four different profiles. In this respect, the present study is different from previous studies.

\section{EXPERIMENTAL SETUP and TEST PROCEDURES}

The airfoils and wing combination of airfoil used for present study had rectangular model and flatten edges. The aspect ratio of the wing models varied from 0.7 to 1.3 in increments of 0.1 and the models had $0.21 \mathrm{~m}$ the chord length. The wing models were produced by gray Polylactic Acid Thermoplastic Polyester (PLA), produced in a 3D printer and the rough surfaces were smoothed with very precision (2500 grit) sandpaper. The performance parameters of the wings were measured in a wind tunnel having low speed in the Aerodynamics Research Laboratory at the Erciyes University Faculty of Aeronautics and Astronautics (EU-FAA). The schematic diagram of the test tunnel is displayed in Figure 1. The wind tunnel is an open and circuit suction type and consists mainly of 8 parts. These are Flow Canal, Flow Regulator Sieve Flanges, Shrinkage Cone, Test Area, Square - Circle Transition Duct, Spreader, Engine and Silencer. The air flow was flatten by two metal Sieve Flanges and was streamed into multiple screens settled in the intake of tunnel. The flow gets through contracted a 6:1 area ratio and arrived in a test section which have square $0.57 \mathrm{~m}$ by $0.57 \mathrm{~m}$ inlet and $0.59 \mathrm{~m}$ by $0.59 \mathrm{~m}$ outlet and of $1.08 \mathrm{~m}$ length. The test section is closed type.

The operating speed range of the wind tunnel is from 3 to $33 \mathrm{~m} / \mathrm{s}$ (fan speed 150-1200 rpm) and has high accuracy hotwire and automatic calibration unit. The flow turbulence intensity measured that was lower than $0.1 \%$ at range of operating speed [12]. An anemometer with a pitot tube connected was used to find the air velocity inside the wind tunnel that based on the chord length of the wing, which corresponds to a speed of $2 \times 10^{5}$ Reynolds number. The lift and drag forces have been measured by 3axis force and torque meter (Load Cell). The models were supported by a strut to the load cell as shown in Figure 2. The strut was attached to 1/4 of the wing cord from the leading edge along the center line of the wing. The experiments were carried out at the angle of attack ranging from -4 to the highest lift point. The angle sweep became at -4 degree and the angle increased by $30 \mathrm{deg}$. with $4 \mathrm{deg}$. increments. After 30 degrees (if the highest lift point exceeds 30 degrees), the increases of angle of attack were 2 degrees. To fully detect max lift and maximum lift/drag points the angle was moved $1 \mathrm{deg}$. increments when necessary. After the test results were recorded the wing model was returned to the initial angle for the other test carried out by changing of angle of attack. At each angle change, it was waited for 30 seconds to wing flicker disappear. Recording of force values was continued for 3 minutes. With the 
loads from the load cell, the A/D Board records 10 values in an each second. Averages of the values recorded for three minutes were taken for every AoA. Each test was performed 3 times and the average of the 3 tests obtained were taken and compared with the numerical results. The uncertainty values of test bench and the experiments are given in Table 1.

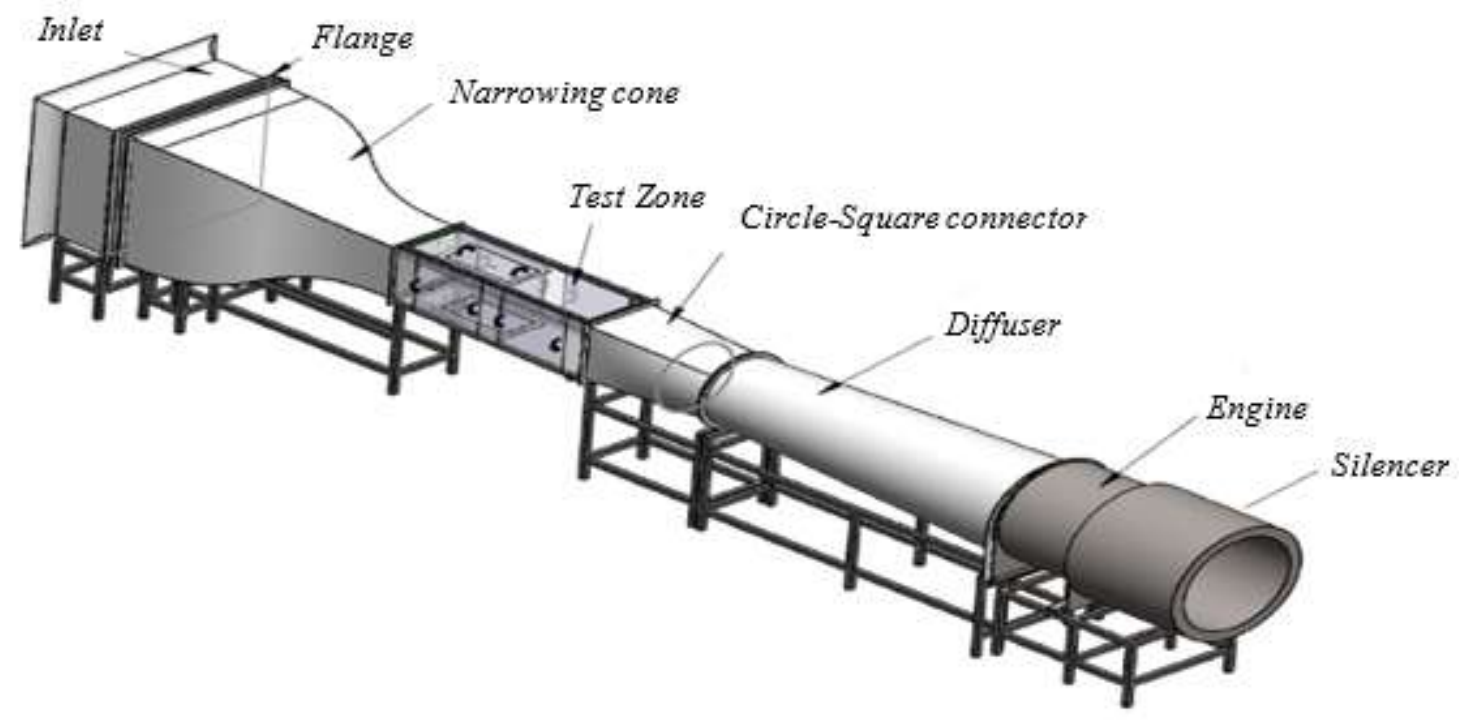

Figure 1. The part of wind tunnel having low speed.

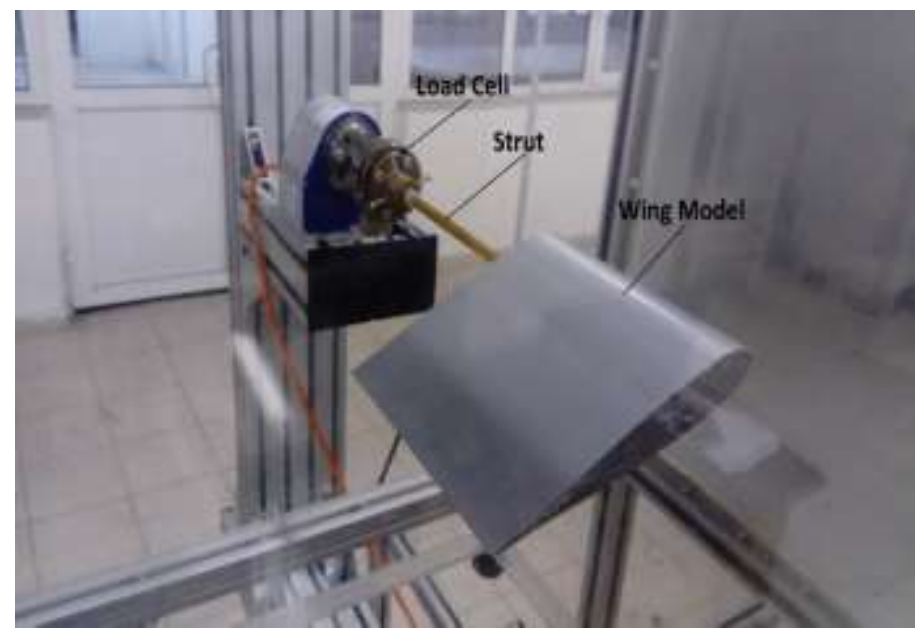

Figure 2. Attachment of wing model to the load cell

Table 1. Reference calculation of total uncertainty (\%) for wing with $A R=1.0$ at $0^{\circ}$ angle of attack.

\begin{tabular}{|c|c|c|c|c|c|c|c|c|}
\hline $\begin{array}{l}\text { Measured } \\
\text { parameter }\end{array}$ & Exp. 1 & Exp. 2 & Exp. 3 & $\begin{array}{c}\text { Average of } \\
\text { Experiments } \\
=\bar{x}\end{array}$ & $\begin{array}{c}\text { Standard } \\
\text { Deviation }=\sigma\end{array}$ & $\begin{array}{l}\% U_{.95} \\
=\frac{2 \sigma * 100}{\bar{x}}\end{array}$ & $\begin{array}{l}\text { Fixed } \\
\text { Error of } \\
\text { Sensor } \\
(\text { FES) } \\
(\%)\end{array}$ & $\begin{array}{l}\text { Total Uncertainty } \\
\text { Measurement (\%) } \\
=\sqrt{\% U_{.95}^{2}+F E S^{2}}\end{array}$ \\
\hline Lift Force & 0.111 & 0.1121 & 0.1105 & 0.1111931 & 0.00076062 & 1.36810511 & 0.03 & 1.368433992 \\
\hline Drag Force & 0.1444 & 0.1418 & 0.1428 & 0.14300666 & 0.00130104 & 1.81956188 & 0.03 & 1.819809179 \\
\hline $\begin{array}{l}\text { Turbulence } \\
\text { Intensity } \\
(15 \mathrm{~m} / \mathrm{s})\end{array}$ & 0.4805 & 0.49 & 0.5015 & 0.49066666 & 0.01051586 & 4.28635640 & 0.2 & 4.291019831 \\
\hline
\end{tabular}


Standard Deviation $=\sigma=\sqrt{\frac{1}{N-1} \sum_{i=1}^{N}\left(x_{i}-\bar{x}\right)^{2}}$

$\sigma=$ Standard Deviation

$\mathrm{N}=$ Number of elements in the array

$\mathrm{X}_{\mathrm{i}}=$ The array's $\mathrm{x}$. member

$\bar{x}=$ Arithmetic Mean of Numbers in Series

\section{NUMERICAL SETUP and VALIDATIONS}

To estimate the approximate aerodynamic performance, the wing profiles, prior to wind tunnel experiments, were first numerically investigated. ANSYS Fluent version 16.1 for simulation was used including the "coupled" algorithm and the second order upwind for solving of the steady-state NavierStokes equations. In order to precisely estimate adverse pressure gradient flows in the flow area on the surface of wing and the transition flow, the SST k- $\omega$ was chosen as the turbulence model $[13,14,15]$. Each calculation consists of 1000 iterations. After approximately 600 iterations, convergence was caught with a residue level of $10^{-4}$.

In this study, the aerodynamic performance of 7 wings, which consisted of four different profiles with different aspect ratios (ranging from 0.7 to 1.3 ), were investigated. The wing planforms are rectangular and have a constant cord length of $\mathrm{c}=0.21 \mathrm{~m}$. The specific features of the wing profile are shown in Table 2. To verify the correctness of lift force and drag force of the wing models, the results compared with wind tunnel tests. Three dimensional mesh models were generated for the wings. The analysis conditions were set to be the same as the wind tunnel experiments. The turbulence intensity is lower than $1 \%$, Reynolds number is $2 \times 10^{5}$, the temperature set to $300 \mathrm{~K}$ and the pressure is $101,325 \mathrm{pa}$. For grid independence; the tests were performed on different cell numbers respectively at $5 \times 10^{5}, 1 \times 10^{6}$, $1,5 \times 10^{6}, 2 \times 10^{6}, 2,5 \times 10^{6}$ and $3 \times 10^{6}$. As can be seen from Figure, the elements mesh number of $2 \times 10^{6}$ was provided grid independence.

Table 2. The shapes and characteristics of the profiles

\begin{tabular}{|c|c|c|c|c|}
\hline Profile & Image of Profile & $\begin{array}{c}\text { Maximum } \\
\text { Thickness/Position } \\
(\% \text { of Chord })\end{array}$ & $\begin{array}{c}\text { Position } \\
\text { on } \\
\text { Camber/Position } \\
(\% \text { of Chord })\end{array}$ & $\begin{array}{c}\text { Model } \\
\text { Wing of } \\
\text { span })\end{array}$ \\
$\begin{array}{c}\text { Views of Profiles on } \\
\text { Model Wing }\end{array}$ \\
\hline $\begin{array}{c}\text { b737a- } \\
\text { il }\end{array}$
\end{tabular}



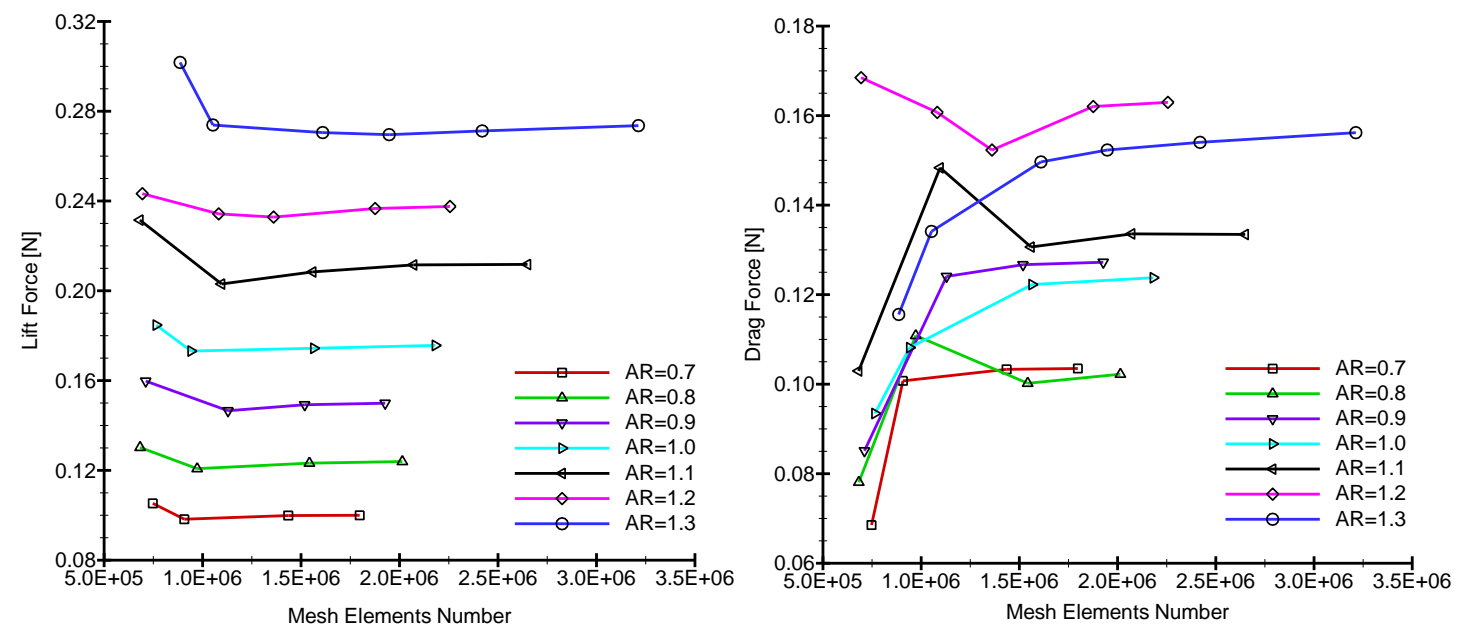

Figure 3. The mesh elements numbers for grid independence (Lift force and Drag force).

This part summarizes the common observations and discusses crucial features of wind tunnel test results and numerical analyses. In a series of angle of attack ranging from $-4^{\circ}$ to the highest lift point (the angle varies depending on profile), a performance analysis of four different profiles and a rectangular wing formed from these profiles was performed at low Reynolds number $\operatorname{Re}=2 \times 10^{5}$. Significant characteristics such as maximum lift, lift/drag coefficient, lift curve inclination, and airflow behaviors were discussed.

The results of numerical analyses have been validated with the data obtained from experimental tests on the wing model for $\mathrm{AR}=0.7, \mathrm{AR}=1.0$ and $\mathrm{AR}=1.3$. Figure 4 shows comparisons of lift and drag coefficients obtained from numerical studies and from experimental tests versus angle of attack at $\operatorname{Re}=2 \times 10^{5}$. As can see from the figure, for angles of attack between $\mathrm{AoA}=-4^{\circ}$ and $16^{\circ}$, the numerical data are nearly the same as the results obtained the experiments. But, at $A o A>16^{\circ}$, this difference in the coefficients of lift force and drag force were comparatively great, and the differences can be explained by the complexity of the flow structure at high angle of attack. When the figure is examined, it can be seen that the curves of $C_{L}$ and $C_{D}$ show the expected trend with the increasing of the angle of attack. Consequently, the curves obtained the numerical studies are generally quite consistent with the experimental results.
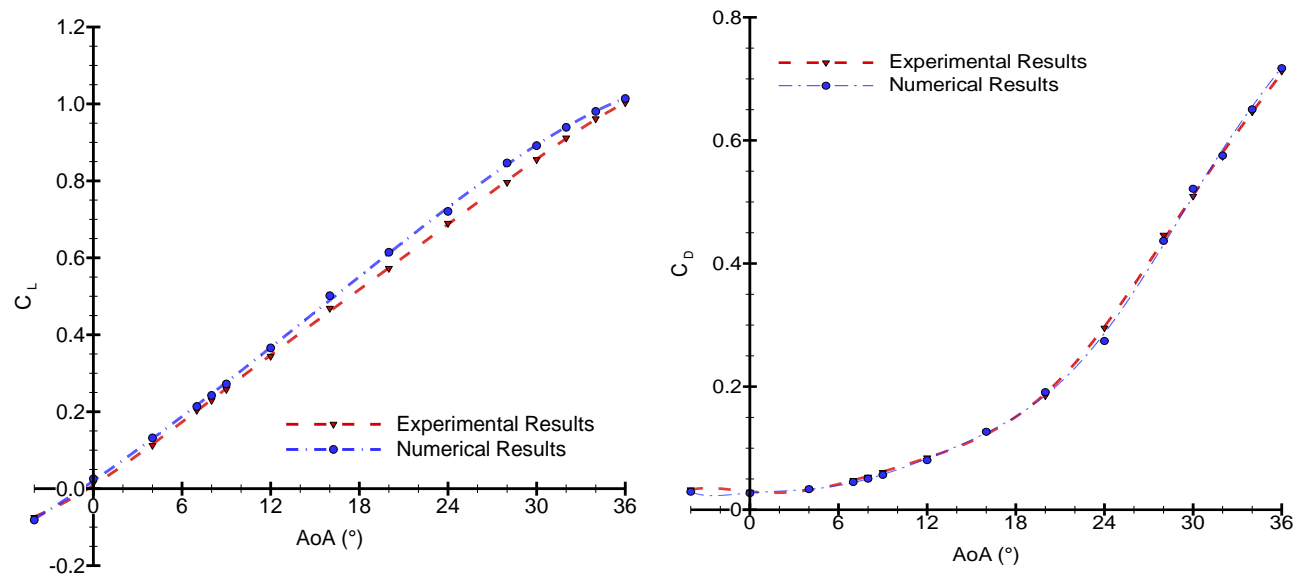

Figure 4-a. Comparison of numerical and experimental results of $C_{L}$ and $C_{D}$ values for $A R=0.7$. 

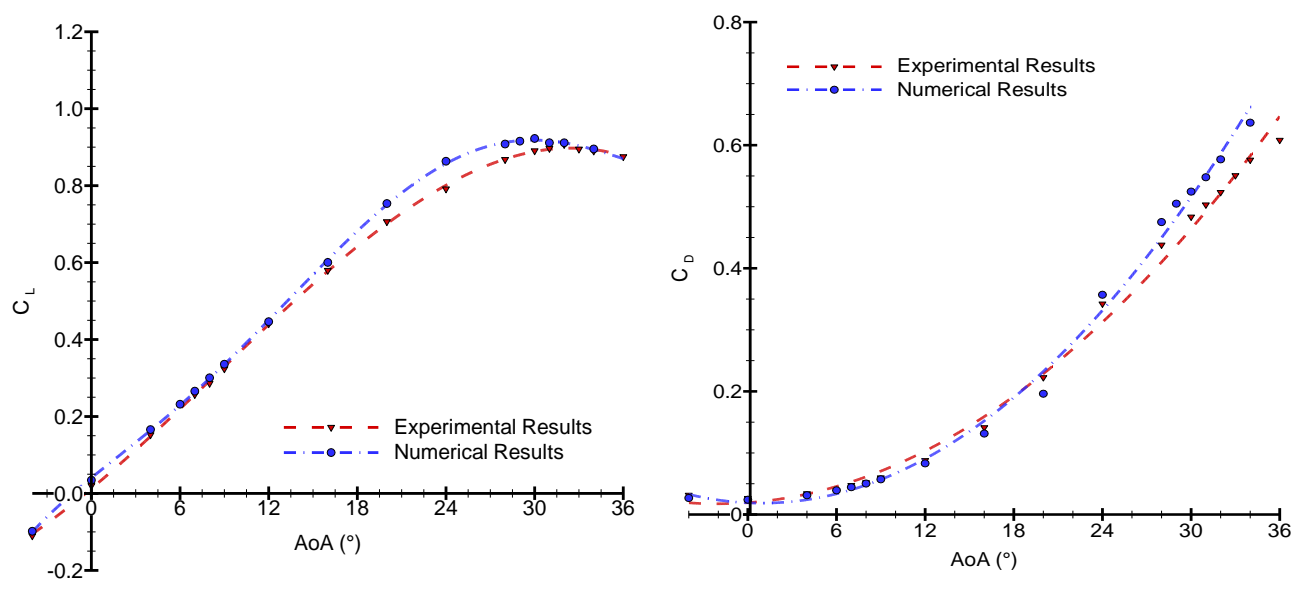

Figure 4-b. Comparison of numerical and experimental results of $C_{L}$ and $C_{D}$ values for $A R=1.0$
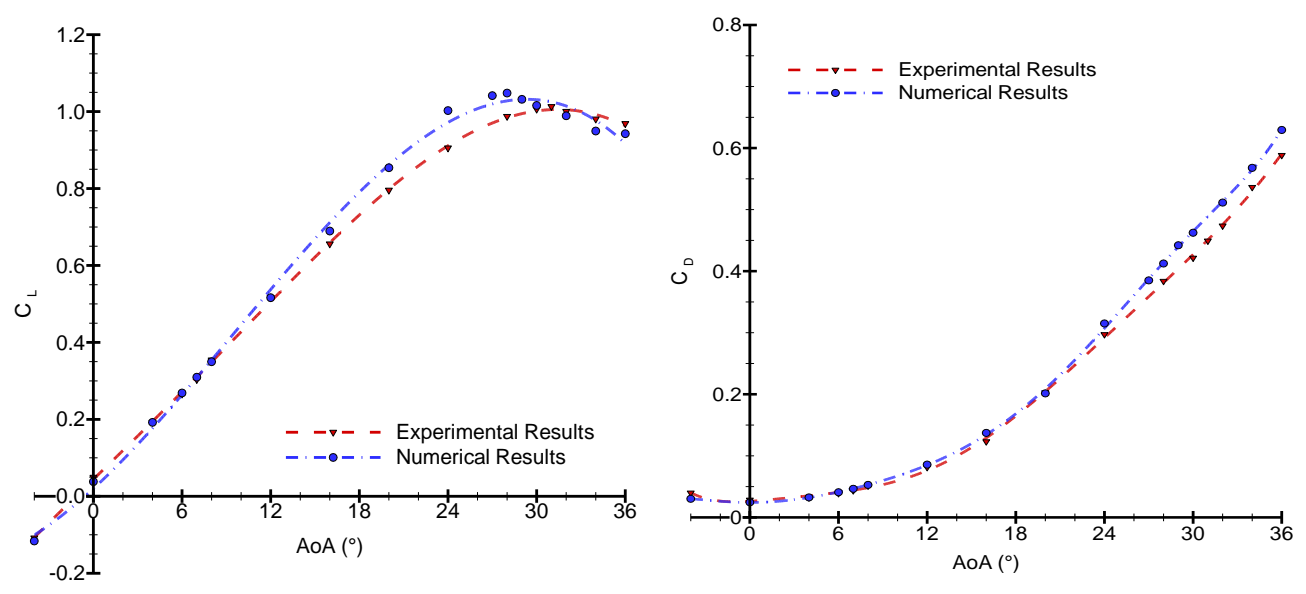

Figure 4-c. Comparison of numerical and experimental results of $C_{L}$ and $C_{D}$ values for $A R=1.3$

\section{RESULTS and DISCUSSIONS}

The $\mathrm{C}_{\mathrm{L}} / \mathrm{C}_{\mathrm{D}}$ ratios versus angle of attack obtained from experiments for different aspect ratios are shown in Figure 5. As you can see from Figure 5(a), the highest $C_{L} / C_{D}$ ratio has been measured as 6.85 from the wing with $A R=1.3$ at $A o A=7^{0}$. Moreover, the highest values for all $A R$ values have been obtained at $A o A=7^{0}-8^{0}$. Above these angles, it can be seen that the $C_{L} / C_{D}$ ratios are decreasing with the increasing of angle for all $A R$ values. At the $A o A=7^{0}-8^{0}$, which is angle obtained the highest $C_{L} / C_{D}$ ratios for all $A R$ values, the lowest ratio has been measured as 4.35 from the wing with $A R=0.7$. As shown in the figure, the increase in the $A R$ values generally leads to a rise in the $C_{L} / C_{D}$ ratio between $A o A=0^{0}$ and $\mathrm{AoA}=30^{\circ}$. As can be seen that the results are compatible with literature studies [16,17]. 


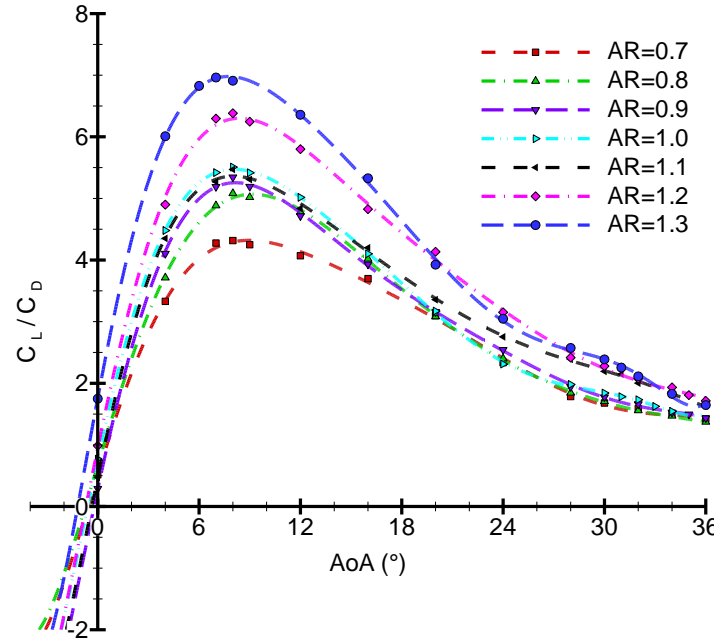

(a)

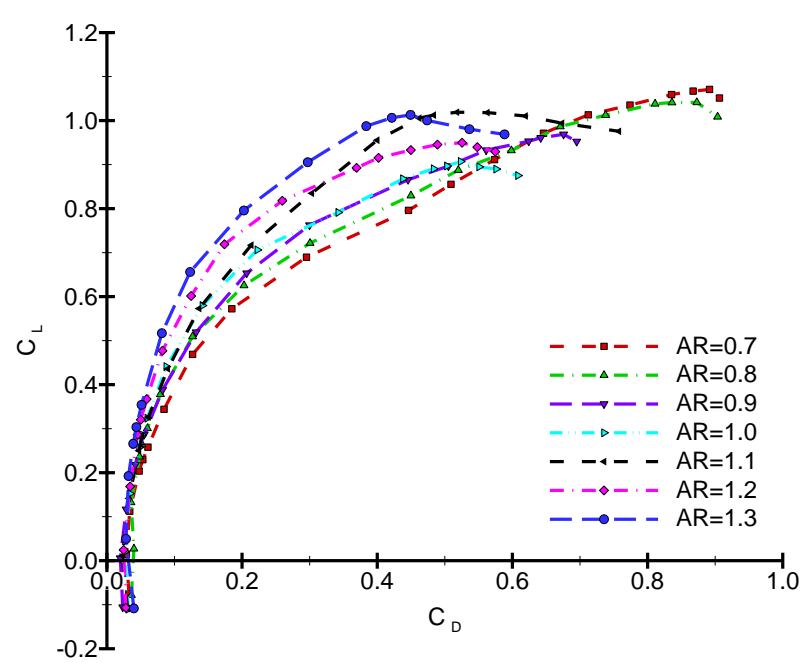

(b)

Figure 5. $C_{L} / C_{D}$ ratios versus angle of attack (a); $C_{L}$ values versus $C_{D}$ values $(b)$ for different aspect ratios.

$C_{L}$ values versus $C_{D}$ values obtained from experiments at different aspect ratios are given in Figure 5(b). With increasing aspect ratio at $C_{L} / C_{D}$ value, while small changes have formed in wings which have $A R$ below 1.1, significant increases have been seen in the wings that have AR between 1.1-1.3. This result coincides with the result of [2]. As can be seen from the figure, high $C_{L}$ values are obtained at lower $C_{D}$ values for $A R=1.3,1.2,1.1$ and 1.0. But, the $C_{L}$ values are tested at higher $C_{D}$ values for $A R=0.9,0.8$ and 0.7. In there, it can be said that the increase in AR values caused a rise in the $C_{L}$ value and a drop in the $C_{D}$ value. The same results can be seen to some literature studies $[18,19]$.

The distributions of pressure coefficients $\left(\mathrm{C}_{\mathrm{P}}\right)$ given with Eq. [1] versus $\mathrm{x} / \mathrm{c}$ for different $\mathrm{AoA}$ and different AR values at different positions on wing model $(\mathrm{z} / \mathrm{b}=5,33.3,66.6$ and $95 \%)$ are shown in Table 3. When the angle of attack is 0 and 8 degrees, the pressure coefficient reaches the peak rapidly near the leading edge, then, the coefficient decreases quickly along the upper surface for all wing models. Up to the trailing edge of the wing models, the coefficient decreases smoothly and gradually without any separation. This behavior looks like an ordinary action of the static pressure distribution on the upper surface of a profile, as can be seen in some literature studies [20,21,22,23]. However, some fluctuations can be seen on the curves for $\mathrm{z} / \mathrm{b}=5 \%$ and $95 \%$ due to the tip vortices.

When the AoA value is 16 and 24 degrees for $\mathrm{z} / \mathrm{b}=33.3 \%$ and $66.6 \%$, the pressure coefficient decreases smoothly and gradually up to the trailing edge of the wing models without any separation. But, when AoA is 16 degrees for $\mathrm{z} / \mathrm{b}=5 \%$ and $95 \%$, the bubbles of separation are seen on the middle and trailing edge of wing models having AR of 1.0 and 1.3 owing to the tip vortices. Moreover, it can be seen that a minor bubble forms at leading edge of wing for $\mathrm{z} / \mathrm{b}=5 \%$. In addition, when AoA is 24 degrees, the bubbles of separation are seen near the trailing edge of wing model having AR of 0.7. When the AoA value is 32 degrees, the bubbles of separation form at the middle and trailing edge of wing models having AR of 0.7 and 1.0 for all positions. Moreover, the flow separation is seen along the upper surface of the wing model having AR of 1.3.

$$
C_{p}=\left[\frac{\left(P-P_{\infty}\right)}{\frac{1}{2} * \rho_{\infty} * U_{\infty}^{2}}\right]
$$

The $\mathrm{P}$ given in Eq. [1] is the static pressure at the point at which pressure coefficient is being evaluated; $\mathrm{P}_{\infty}$ : is the static pressure in the freestream; $\rho_{\infty}$ : is the freestream density and $\mathrm{U}_{\infty}$ : is the freestream velocity of the air flow. 
Table 3-a. The distributions of pressure coefficients $\left(C_{P}\right)$ versus $x / c$ for different AoA and different AR values (at $z / b=5 \%$ ).

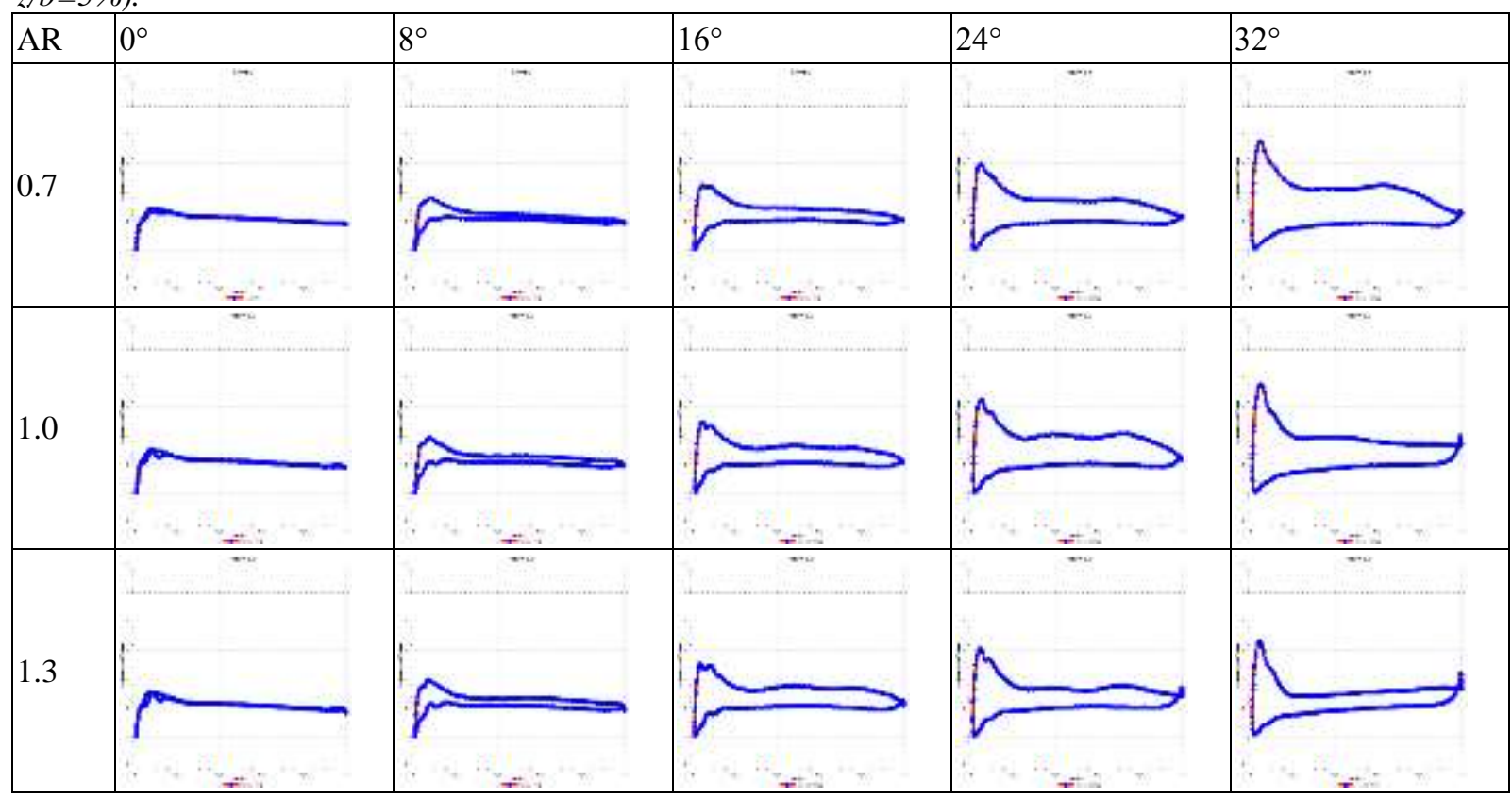

Table 3-b. The distributions of pressure coefficients $\left(C_{P}\right)$ versus $x / c$ for different AoA and different AR values (at $z / b=33.3 \%$ ).

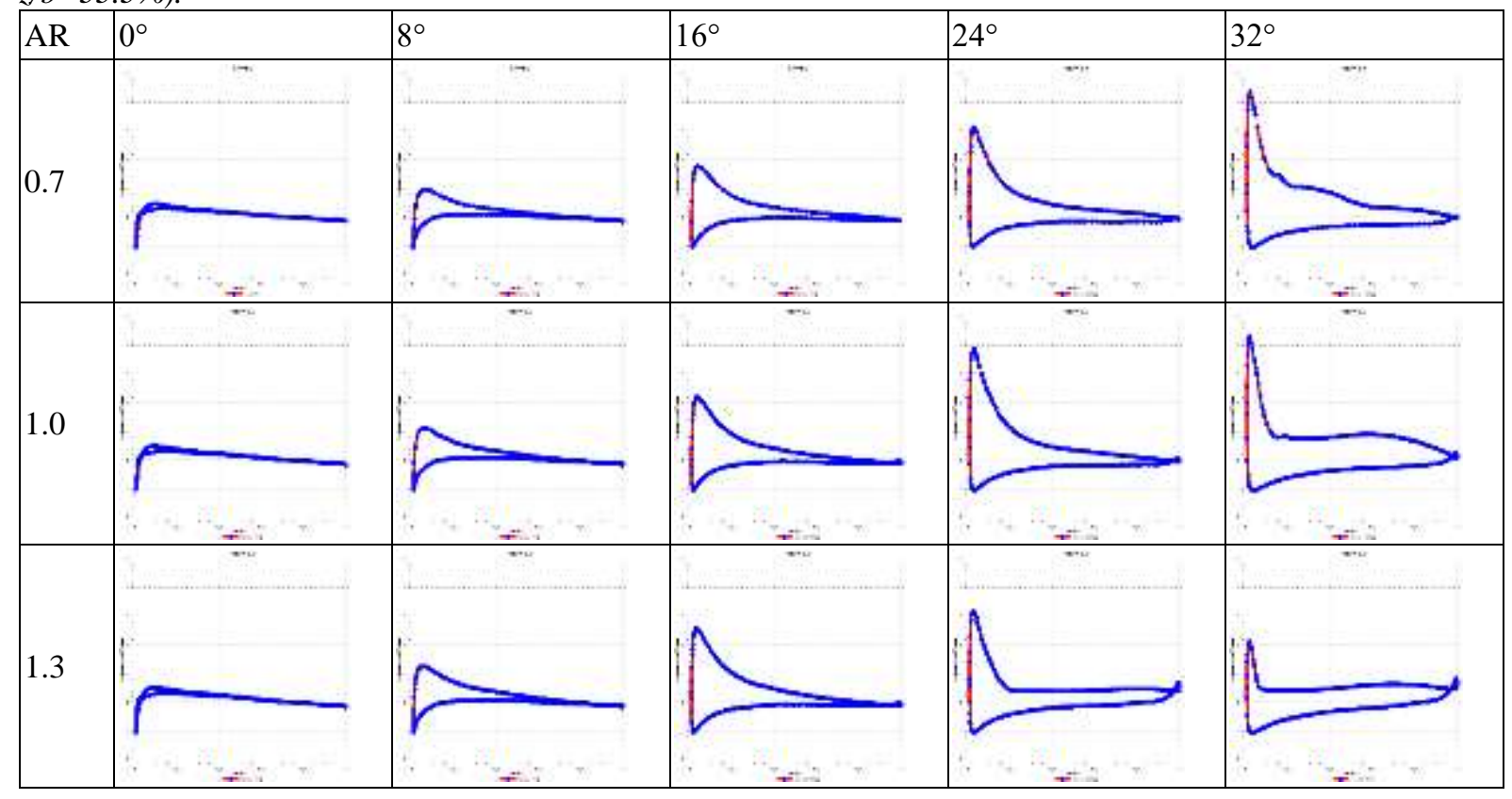


Table 3-c. The distributions of pressure coefficients $\left(C_{P}\right)$ versus $x / c$ for different AoA and different AR values (at $z / b=66.6 \%)$.

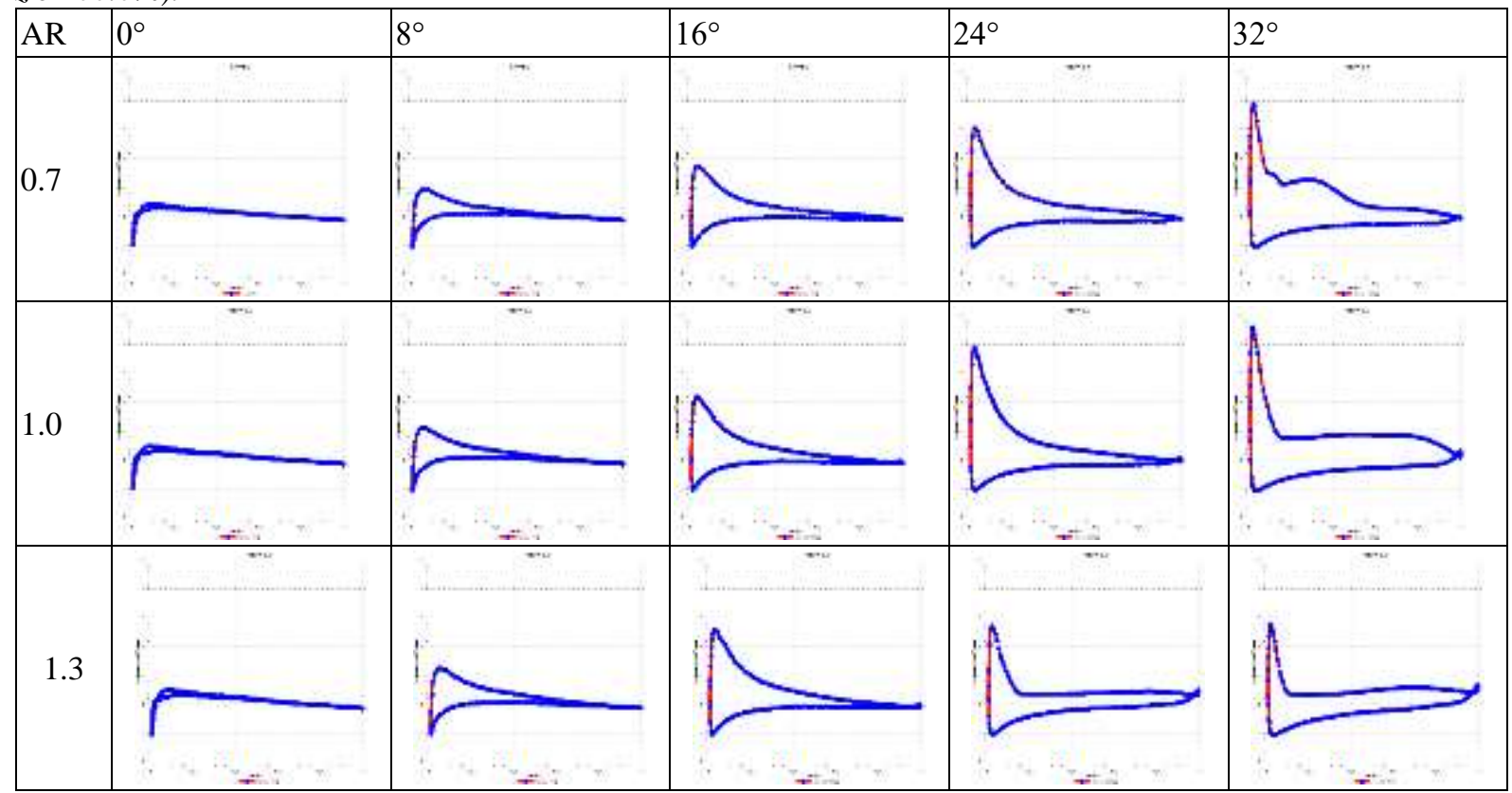

Table 3-d. The distributions of pressure coefficients $\left(C_{P}\right)$ versus $x / c$ for different AoA and different AR values (at $z / b=95 \%$ ).

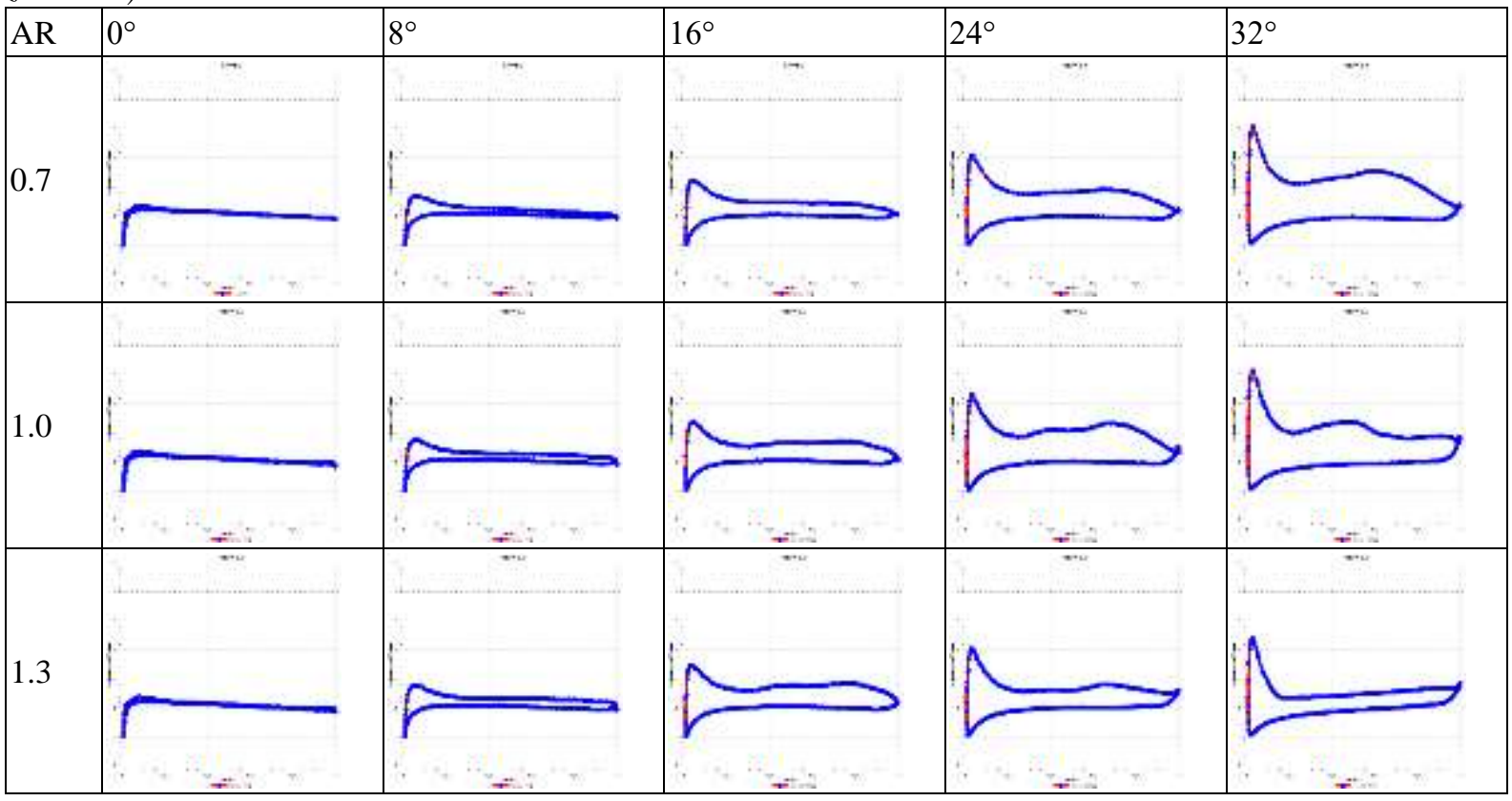

When the distributions of pressure coefficients at $\mathrm{z} / \mathrm{b}=5 \%$ compare with the values at $\mathrm{z} / \mathrm{b}=95 \%$ it $\mathrm{can}$ be seen a minor bubble forms at leading edge for the positions at $\mathrm{z} / \mathrm{b}=5 \%$. Profile a at $\mathrm{z} / \mathrm{b}=5 \%$ has more thickness leading edge than Profile $\mathrm{d}$ at $\mathrm{z} / \mathrm{b}=95 \%$, as can be seen from Table 2 , so the thickness leads to a minor bubble at leading edge. When the distributions of pressure coefficients at $\mathrm{z} / \mathrm{b}=33.3 \%$ compare with the values at $\mathrm{z} / \mathrm{b}=66.6 \%$, it can be said that the distributions of pressure coefficients have not been affected by the changing of profile model. 
Table 4. The changes of velocity with streamline on the wing model for different AoA and different AR values.

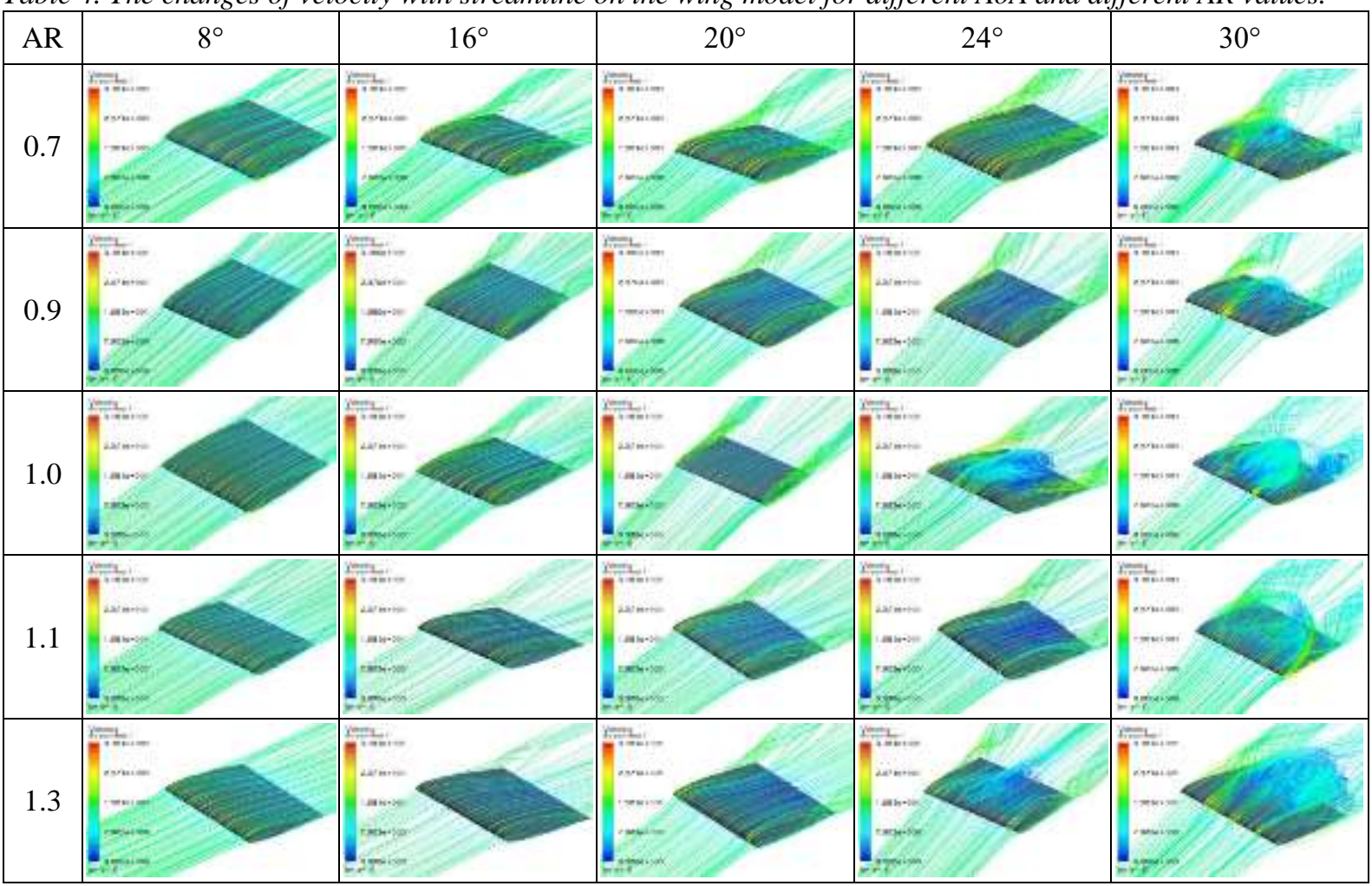

The changes of velocity with streamline on the wing model for different AoA and different AR values are given in Table 4. It is seen from the table that the velocity streamlines are flowed as laminar on the wing model until $\mathrm{AoA}=20^{\circ}$. With increasing angle of attack, the flow separation has occurred about $16^{\circ}$ angle and the separation bubbles of flow are seen at $24^{\circ}$ angle for all AR values. Moreover, the bubbles are quite clear for 1.1 and 1.3 AR values, while the bubbles are less obvious for the other AR values. When looked the streamlines at the high angle of attack, it can be seen that the separation of flow is generally more obvious with the increasing of AR values. In addition, it can be observed that the flow separations start in the moderate of the up surface of the wing and in areas near the trailing edge. Moreover, it can be seen the figures that the vortexes of wingtip have become strong with the decreasing of AR values and the increase of angle of attack. This result matches the results of the study [5].

\section{CONCLUSIONS}

In this study, the influence of aspect ratio on the aerodynamically performances and flow separation behavior were investigated on a model wing made up four different profiles. The experimental and numerical studies were carried out at different angles of attack (AoA) ranging from $-4^{\circ}$ to $40^{\circ}$ and at the $2 \times 10^{5} \mathrm{Re}$ on wing models having different aspect ratios (0.7-1.3). The main results obtained from the studies are presented below.

With the variation of aspect ratio, relatively small changes have formed in $C_{L} / C_{D}$ on wings which have 1.0 AR and less, but crucial increases have formed in between 1.1-1.3 wings. So, the highest $C_{L} / C_{D}$ ratio has been measured as 6.85 from the wing with $\mathrm{AR}=1.3$ at $\mathrm{AoA}=7^{0}$. These results show very good compatibility with the results of some studies [2] in the literature. 
The rising in AR values caused a boost in the coefficient of lift and relatively small descent in the coefficient of drag. So, the increasing of $A R$ values leads to an increase in the ratio of $C_{L} / C_{D}$, which is coherent with literature studies.

Similar to the study of literature [5], with increasing of AoA, it was seen that the tip vertexes becoming bigger and stronger. Moreover, the flow separated from the upper surface about $16^{\circ}$ angles and the separation bubbles have formed at $24^{\circ}-320$ for all AR values. From the pressure coefficient graphs, it is seen that a portion of this separated flow tends to re-attached on the surface.

The increase in AR and in AoA triggered the flow separation. It was observed that the size of the separation bubbles occurring at high angles increased both in transverse and longitudinal direction as AR increased.

\section{REFERENCES}

[1] Mizoguchi, M, Itoh, H. Effect of aspect ratio on aerodynamic characteristics at low Reynolds numbers. AIAA Journal 2013; 51(7): 1631-1639. http://dx.doi.org/10.2514/1.J051915

[2] Mizoguchi, M, Kajikawa, YK, Itoh, H. Aerodynamic characteristics of low-aspect-ratio wings with various aspect ratios in low Reynolds number flows. Transactions of The Japan Society for Aeronautical and Space Sciences 2016; 59(2): 56-63. https://doi.org/10.2322/tjsass.59.56

[3] Torres, GE, Mueller, TJ. Low-aspect-ratio wing aerodynamics at low Reynolds numbers. AIAA Journal 2004; 42(5): 865-873. https://doi.org/10.2514/1.439

[4] Traub, LW. Aerodynamic impact of aspect ratio at low Reynolds number. Journal of Aircraft 2013; 50(2): 626-634. https://doi.org/10.2514/1.C031980

[5] Liu, YC, Hsiao, FB. Experimental investigation on critical Reynolds numbers aerodynamic properties of low aspect ratios wings. Procedia Engineering 2014; 79: 76 - 85.doi: 10.1016/j.proeng.2014.06.313

[6] Ananda, GK, Sukumar, PP, Selig, MS. Measured aerodynamic characteristics of wings at low Reynolds numbers. Aerospace Science and Technology 2015; 42: 392-406. http://dx.doi.org/10.1016/j.ast.2014.11.016

[7] DeVoria, AC, Mohseni, K. The effect of aspect ratio on the near-wake flow of rectangular wings. 54th AIAA Aerospace Sciences Meeting, AIAA SciTech Forum, AIAA 2016-0857, January 2016, California, pp. 1-10. https://doi.org/10.2514/6.2016-0857

[8] Zhang, Z. Hubner, JP, Timpe, A, Ukeiley, L. Abudaram, Y. and Ifju, P. Effect of aspect ratio on flat - plate membrane airfoils," 50th AIAA Aerospace Sciences Meeting including the New Horizons Forum and Aerospace Exposition; AIAA 2012-1084, 9-12 January 2012, Tennesse, pp. 1-15. https://doi.org/10.2514/6.2012-1084

[9] Angulo, IA, Ansell, PJ. Influence of aspect ratio on dynamic stall of a finite wing. AIAA Aerospace Sciences Meeting, AIAA SciTech Forum, AIAA 2018-0546, Januar 2018, Florida, pp. 1-14. https://doi.org/10.2514/6.2018-0546

[10]Okamoto, M. Azuma, A. Aerodynamic characteristics at low Reynolds number for wings of various planforms. AIAA Journal 2011; 49(6): 1135-1150. https://doi.org/10.2514/1.J050071

[11]Shields, M, Mohseni, K. Effects of sideslip on the aerodynamics of low-aspect-ratio low-Reynolds-number wings. AIAA Journal 2012; 50(1): 85-99. https://doi.org/10.2514/1.J051151

[12]Yilmaz, İ, Çam, Ö, Taştan, M, Karci, A. Experimental investigation of aerodynamic performance of different wind turbine airfoils. Politeknik 2016; 9(4): 577-584. DOI:10.2339/2016.19.4 577-584

[13]Chen, PW, Bai, CJ, Wang, WC. Experimental and numerical studies of low aspect ratio wing at critical Reynolds number. European Journal of Mechanics B/Fluids 2016; 59: 161-168. http://dx.doi.org/10.1016/j.euromechflu.2016.06.005

[14]Menter, FR. Two-equation eddy-viscosity turbulence models for engineering applications. AIAA Journal 1994; 32(18): 1598-1605. https://doi.org/10.2514/3.12149

[15]Gabor, OŞ, Koreanschi, A, Botez, RM, Mamou, M, Mebarki, Y. Numerical simulation and wind tunnel tests investigation and validation of a morphing wing-tip demonstrator aerodynamic performance. Aerospace Science and Technology 2016; 53: 136-153. https://doi.org/10.1016/j.ast.2016.03.014

[16]Noughabi, AK, Tadjfar, M. Cross-wind influence on low aspect ratio wings at low reynolds numbers. Proceedings of the ASME 2013 Fluids Engineering Division Summer Meeting FEDSM 2013, FEDSM2013- 
16523, 7-11July 2013, Nevada, pp. 1-9. DOI: 10.1115/FEDSM2013-16523

[17]Narayan, G, John, B. Effect of winglets induced tip vortex structure on the performance of subsonic wings. Aerospace Science and Technology 2016; 58: 328-340. https://doi.org/10.1016/j.ast.2016.08.031

[18]Chattot, JJ, Hafez, MM. Flow Past Large and Moderate Aspect RatioWings, Theoretical and Applied Aerodynamics, USA: Springer Science+Business Media Dordrecht 2015.

[19]Kruyt, JW, Quicazán-Rubio, EM, van Heijst, GF, Altshuler, DL, Lentink, D. Hummingbird wing efficacy depends on aspect ratio and compares with helicopter rotors. Journal of the Royal Society Interface 2014; 11: 1-12. https://doi.org/10.1098/rsif.2014.0585

[20]Lin, JCM, Pauley, LL. Low-Reynolds-number separation on an airfoil. AIAA Journal 1996; 34(8): $1570-1577$. https://doi.org/10.2514/3.13273

[21]Zhang, W, Zhang, Z, Chen, Z, Tang, Q. Main characteristics of suction control of flow separation of an airfoil at low Reynolds numbers. European Journal of Mechanics B/Fluids 2017; 65: 88-97. http://dx.doi.org/10.1016/j.euromechflu.2017.01.010

[22]Hu, H, Yang, Z. An experimental study of the laminar flow separation on a low-reynolds-number airfoil. Journal of Fluids Engineering 2008; 130; 051101: 1-11. DOI: 10.1115/1.2907416

[23]Worasinchai, S, Ingram, G, Dominy, R. A Low-Reynolds-number, high-angle-of-attack investigation of wind turbine aerofoils. Proceedings of The Institution of Mechanical Engineers Part A-Journal of Power and Energy 2011; 225(6): 748-763. https://doi.org/10.1177/0957650911405411 